\title{
Facile Synthesis Polyethylene Glycol Coated Magnetite Nanoparticles for High Colloidal Stability
}

\author{
Mun Foong Tai, Chin Wei Lai, and Sharifah Bee Abdul Hamid \\ Nanotechnology \& Catalysis Research Centre (NANOCAT), Institute of Postgraduate Studies (IPS), University of Malaya, \\ 3rd Floor, Block A, 50603 Kuala Lumpur, Malaysia \\ Correspondence should be addressed to Sharifah Bee Abdul Hamid; sharifahbee@um.edu.my
}

Received 22 July 2016; Revised 18 September 2016; Accepted 20 September 2016

Academic Editor: Masoud Rahman

Copyright (C) 2016 Mun Foong Tai et al. This is an open access article distributed under the Creative Commons Attribution License, which permits unrestricted use, distribution, and reproduction in any medium, provided the original work is properly cited.

Polyethylene glycol (PEG) is one of the most frequently used synthetic polymers for surface modifications of magnetite nanoparticles (MNPs) to provide a new opportunity for constructing high colloidal stability. Herein, a facile in situ coprecipitation technique is described for the synthesis of PEG coated MNPs using ammonium hydroxide as the precipitating agent. The structure and morphology of the prepared PEG coated MNPs samples were characterized by Fourier transform infrared (FTIR) spectroscopy, $\mathrm{X}$-ray spectroscopy, thermogravimetric analysis (TGA), and the high resolution transmission electron microscopy (HRTEM). In this study, all samples demonstrated hydrodynamic size in the range of 32 to $43 \mathrm{~nm}$ with narrow size distribution. In addition, the magnetic properties of resultant samples were investigated using a vibrating sample magnetometer (VSM) to reveal the superparamagnetic behaviour with saturation magnetization. The saturation magnetization of PEG coated MNPs samples was in the range of 63 to $66 \mathrm{emu} / \mathrm{g}$ at $300 \mathrm{~K}$. Interestingly, it was found that $1.0 \mathrm{~g}$ of PEG coated MNPs exhibited high colloidal stability in a basic solution $(\mathrm{pH}=10)$ and nitrile (NBR) latex up to 21 days as compared to the unmodified MNPs during the sedimentation test.

\section{Introduction}

In the past decade, magnetite nanoparticles (MNPs) have been intensively studied due to their many unique properties that could be applied in the field of biotechnology, biomedical, material science, engineering, and environmental pollution management [1]. In fact, MNPs are widely used in biomedical applications, such as drug delivery, diagnostic magnetic resonance imaging (MRI), thermal therapy, and cell labelling [2]. Nowadays, MNPs are the primary choice for most of the biomedical applications due to their low toxicity, biocompatibility, superparamagnetic behaviour, and chemical stability [3]. However, MNPs experience strong van der Waals and magnetic attractions between particles, which might cause the MNPs dispersion to be very unstable and all particles to be prone to aggregation [4]. To prevent aggregation or coagulation phenomena in colloidal system, the MNPs have to be stabilized against coagulation due to the electrostatic or steric repulsion forces $[5,6]$. Therefore, a suitable surface functionalization and choice of solvent are crucial in order to achieve sufficient repulsive interactions to prevent agglomeration problem in MNPs colloidal system. Considerable efforts have been exerted to obtain a stable colloidal solution via surface modification strategy [7]. In this manner, modified MNPs can consist of long-chain organic ligands or inorganic/organic polymers, where these ligands or polymers can be introduced during (in situ coating) or after (postsynthetic coating) synthesis stage [8]. When polymer or organic molecules are attached to a charged particle surface, the MNPs can be stabilized by combining both steric stabilization and electrostatic stabilization [9].

In the present study, polyethylene glycol (PEG) was selected as a promising synthetic polymer for surface modifications of MNPs [10]. As a matter of fact, PEG is a hydrophilic, highly water soluble, biocompatible, nonantigenic, and protein-resistant polymer. The solubility of PEG in water has been attributed to its hydration with bound water molecules, which increases with polymer molecular weight [11]. In addition, PEGs are FDA-approved excipients in numerous pharmaceutical formulations due to their biocompatibility property [12]. To the best of our knowledge, the literature regarding the formation of PEG coated MNPs via a facile in situ 
TABLE 1: Hydrodynamic size and polydispersity index of MNPs with different loading amount of PEG $600 \mathrm{Da}$.

\begin{tabular}{lccc}
\hline Sample & Hydrodynamic size $(\mathrm{nm})$ & Polydispersity index $($ PDI) & Zeta potential $(\mathrm{mV})$ \\
\hline Uncoated & 42.9 & 0.214 & -29.8 \\
$0.6 \mathrm{~g}$ & 44.1 & 0.200 & -35.9 \\
$0.8 \mathrm{~g}$ & 36.7 & 0.188 & -41.1 \\
$1.0 \mathrm{~g}$ & 35.5 & 0.178 & -43.6 \\
$2.0 \mathrm{~g}$ & 35.9 & 0.176 & -45.6 \\
$3.0 \mathrm{~g}$ & 32.3 & 0.168 & -45.8 \\
\hline
\end{tabular}

$$
\mathrm{H}-\left[\mathrm{O}-\mathrm{C}-\stackrel{\mathrm{H}_{2}}{\mathrm{C}} \underset{\mathrm{H}_{2}}{-}-\mathrm{OH}\right.
$$

FIgURE 1: Chemical structure of PEG as a promising synthetic polymer.

coprecipitation technique for the improvement of colloidal stability in a basic solution $(\mathrm{pH}=10)$ and nitrile $(\mathrm{NBR})$ latex is still lacking. Therefore, this study aims to optimize the loading amount of PEG on MNPs towards to the high colloidal stability performance in a basic solution $(\mathrm{pH}=10)$ and nitrile (NBR) latex. The chemical structure of PEG is presented in Figure 1.

\section{Materials and Methods}

2.1. Materials. Ferrous chloride tetrahydrate $\left(\mathrm{FeCl}_{2} \cdot 4 \mathrm{H}_{2} \mathrm{O}\right.$, Merck), ferric chloride hexahydrate $\left(\mathrm{FeCl}_{3} \cdot 6 \mathrm{H}_{2} \mathrm{O}\right.$, Sigma $\geq$ 97\%), ammonium hydroxide $\left(\mathrm{NH}_{4} \mathrm{OH}\right.$, Sigma 28\%), and polyethylene glycol (PEG) were purchased from Merck.

2.2. Methods. Ferrous chloride tetrahydrate, ferric chloride hexahydrate, and ammonium hydroxide were used for the synthesis of MNPs. First, ferrous chloride and ferric chloride with molar ratio of $1: 1.5$ were dissolved in deionized water. Next, 3.00 M of ammonium hydroxide solution was added by Autotitrator (Mettler Toledo, T50) at a speed of $5.0 \mathrm{~mL} \mathrm{~min}^{-1}$ into the solution to reach a fixed volume. These reactions were carried out at $60^{\circ} \mathrm{C}$ under oxidizing environment and stirring was continued for another 90 minutes. The solution was stirred mechanically at $350 \mathrm{rpm}$ by mechanical homogenizer throughout the experiment. PEG coated MNPs samples were fabricated using in situ coating technique, where PEG $600 \mathrm{Da}$ with different loading amount were introduced into the iron salts solution before the addition of ammonium hydroxide solution. The loading amount of PEG $600 \mathrm{Da}$ was varied as $0.6 \mathrm{~g}, 0.8 \mathrm{~g}, 1.0 \mathrm{~g}, 2.0 \mathrm{~g}$, and $3.0 \mathrm{~g}$, respectively. The resultant black precipitate was isolated by magnetic decantation and dried at room temperature after washing 3 times with deionized water.

2.3. Characterization. Dynamic Light Scattering (DLS) technique is used to measure hydrodynamic size of the prepared MNPs at pH 10 condition using Malvern Zetasizer NanoZS [Measurement range: $0.3 \mathrm{~nm}-10.0$ microns $*$ (diameter)]. This technique measures the diffusion of particles moving under Brownian motion and converts this to size and a size distribution using the Stokes-Einstein relationship. In order to obtain more reliable information about the hydrodynamic size, CONTIN was applied in our DLS system. Meanwhile, crystalline phase of MNPs was studied by X-ray diffraction using $\mathrm{Cu} \mathrm{K} \alpha$ radiation (XRD, $\lambda=1.5406 \AA$, Bruker axs D8 Advance diffractometer). In addition to that, the MNPs were also characterized by Fourier transform infrared spectroscopy (Bruker ifs 66/s FTIR spectrometer) and thermogravimetric analysis (Mettler Toledo, TGA/SDTA-851). The high resolution transmission electron microscopy (HRTEM) study was carried out on an electron microscopy instrument (JEM-2100F) with accelerating voltage $200 \mathrm{kV}$ for providing the better resolution image (with aberration correction). The average particle size was measured and recorded for at least 20 particles from the HRTEM image. The powders for HRTEM were dispersed in ethanol and the suspension was then dropped on copper grid. The magnetic properties of MNPs were investigated in a vibrating sample magnetometer (VSM, LakeShore 7400; Chicago, IL, USA) at $300 \mathrm{~K}$.

\section{Results and Discussion}

The effect of different loading amount of PEG $600 \mathrm{Da}$ on MNPs towards the high colloidal stability performance is discussed. The hydrodynamic diameter and size distributions of MNPs with different loading of PEG 600 Da were shown in Table 1 .

It is worthy to note that the addition of PEG $600 \mathrm{Da}$ to MNPs resulted in a smaller hydrodynamic size and narrower size distribution. In addition to that, it could be observed that the zeta potential for uncoated MNPs sample exhibited the negative charge value of about $-29.8 \mathrm{mV}$. The main reason was mainly due to the $\mathrm{OH}$ - ions associated with the surface of MNPs at pH 10 basic medium. However, zeta potential value for modified MNPs was increasing from $\sim 35 \mathrm{mV}$ up to $\sim 46 \mathrm{mV}$ after the addition of PEG from $0.6 \mathrm{~g}$ to $3.0 \mathrm{~g}$. In fact, these obtained results indirectly inferred that PEG segment coated on MNPs samples could lead to a more pronounced electrostatic stabilization and better water dispersibility performance as compared to the MNPs [13].

It is well-known fact that surface morphology change of modified MNPs is closely related to their crystal growth. Therefore, XRD analysis was conducted to investigate the influence of their phase transformation on uncoated MNPs sample and different loading amount of PEG coated MNPs samples. According to Figure 2, all tested MNPs samples exhibited almost similar pattern with different peaks intensity 


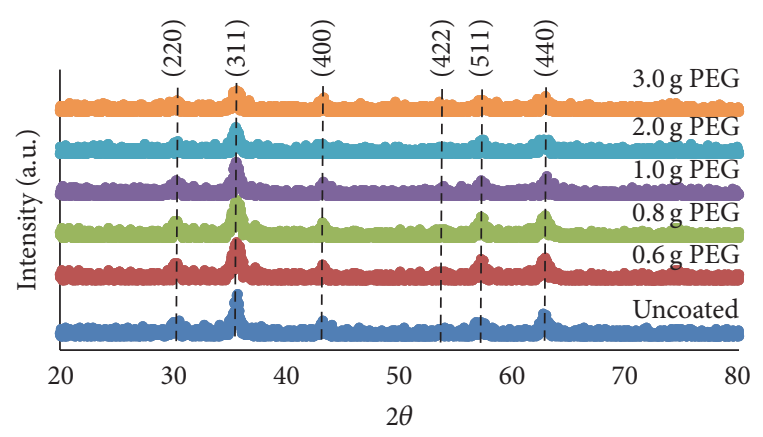

FIGURE 2: XRD patterns of MNPs with different loading amount of PEG 600 Da.

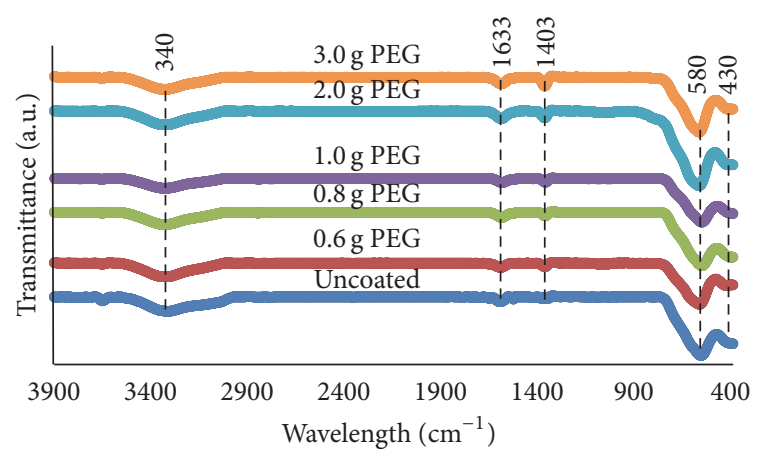

FIGURE 3: FTIR spectra of MNPs with different loading amount of PEG 600 Da.

from the plotted XRD patterns. The positions and relative intensities of all diffraction peaks fit well with those from the JCPDS card (19-0629) for magnetite with (220), (311), (400), (551), and (440) peaks at about $2 \theta \approx 30^{\circ}, 35^{\circ}, 43^{\circ}, 57^{\circ}$, and $63^{\circ}$, respectively [14]. However, the diffraction peaks are weaker in terms of peak's intensity and much broader for the modified MNPs samples when increasing the loading amount of PEG $600 \mathrm{Da}$. These results showed that the increasing of loading amount of PEG showed a reduction of MNPs crystallinity [15]. The estimated crystallite size of uncoated MNPs was decreased accordingly when the loading amount of PEG was increasing from $0.6 \mathrm{~g}$ up to $3.0 \mathrm{~g}$. The estimated crystallite sizes of uncoated MNPs sample and PEG $(0.6 \mathrm{~g}, 0.8 \mathrm{~g}, 1.0 \mathrm{~g}$, $2.0 \mathrm{~g}$, and $3.0 \mathrm{~g}$ ) coated on MNPs samples are approximately $13.60 \mathrm{~nm}, 12.30 \mathrm{~nm}, 11.90 \mathrm{~nm}, 10.70 \mathrm{~nm}, 10.40 \mathrm{~nm}$, and $9.30 \mathrm{~nm}$, respectively. These results further ascertained that the addition of the polymer PEG 600 Da plays a crucial role in controlling the size of the MNPs.

Next, FTIR analysis was carried out to further investigate the adsorption of the PEG on the surface of synthesized MNPs. Figure 3 shows the FTIR spectra of synthesized MNPs coating with different amount of PEG 600. Four peaks at $430 \mathrm{~cm}^{-1}, 580 \mathrm{~cm}^{-1}, 1630 \mathrm{~cm}^{-1}$, and $3400 \mathrm{~cm}^{-1}$ appeared in the spectrum of uncoated MNPs. The peaks at $430 \mathrm{~cm}^{-1}$ and $580 \mathrm{~cm}^{-1}$ were assigned to magnetite phase while the peaks at $1633 \mathrm{~cm}^{-1}$ and $3400 \mathrm{~cm}^{-1}$ were attributed to the stretching $\mathrm{OH}$ vibration of water molecules. In PEG parameter, the peak obtained at $\sim 1633 \mathrm{~cm}^{-1}$ was assigned to the stretching of $\mathrm{OH}$ band and asymmetric carboxylate (COO-) stretching vibration, while the peak at $\sim 1403 \mathrm{~cm}^{-1}$ was attributed to the vibration of - $\mathrm{CH}$. These peaks corresponding to the bonds $\mathrm{CH}$ and - $\mathrm{COO}$ - are the strong evidence to show that the synthesized MNPs surface has been coated with PEG and coordinated through carbonyl group in PEG $[15,16]$. The characteristic peaks of PEG polymer at around $950 \mathrm{~cm}^{-1}$ and $1080 \mathrm{~cm}^{-1}$ that correspond to the $\mathrm{C}-\mathrm{C}$ stretch and $\mathrm{C}-\mathrm{O}-\mathrm{C}$ stretch disappeared in the FTIR spectrum of PEG coated MNPs samples. This result indicates a dipole-cation binding between the ether group of PEG and the positive charge of MNPs [17].

Figure 4 shows the images obtained by high resolution transmission microscopy (HRTEM) for two selected samples, namely, uncoated MNPs and PEG (1.0 g) coated MNPs. From Figure 4(a), round shaped particles with an average particle size of $15.5 \mathrm{~nm} \pm 3.5 \mathrm{~nm}$ were observed for the uncoated MNPs. Nyirö-Kósa and coresearchers claimed that the shape changes correlated with the crystallite size and the samples with crystal size of smaller than $\sim 25 \mathrm{~nm}$ are said to contain irregular and round shaped particles [18]. Nevertheless, addition of sufficient amount of PEG could act as a stabilizer and dispersing agent; hence MNPs of well-defined and homogeneous shape with smaller particle size, about $14.1 \mathrm{~nm} \pm 2.3 \mathrm{~nm}$ (Figure 4(b)), were produced. The average particle size was in good agreement with XRD results, where the crystallite sizes obtained for uncoated MNPs and PEG (1.0 g) coated MNPs were approximately $13.6 \mathrm{~nm}$ and $12.3 \mathrm{~nm}$, respectively. These results also clearly indicate that the synthesized MNPs were single crystal and in single-domain state [19].

Figure 5 shows the TGA curves of the MNPs with different loading amount of PEG $600 \mathrm{Da}$. According to Figure 5, a slight weight loss at temperature below $100^{\circ} \mathrm{C}$ could be noticed for all of the tested samples. In this manner, the weight loss of MNPs at below $100^{\circ} \mathrm{C}$ is likely to be caused by the contained water [20]. The moisture content found in all samples was about $0.33 \%$ up to $1.35 \%$ based on calculation. For uncoated MNPs, a weight loss of $3.68 \%$ was observed at $100-600^{\circ} \mathrm{C}$. The main reason might be attributed to the decomposition of hydroxyl group on the surface of MNPs [21]. The TGA curves for PEG coated MNPs samples showed a sharp fall over the range of temperature from $160^{\circ} \mathrm{C}$ to $450^{\circ} \mathrm{C}$ under the second stage of weight reduction as presented in Figure 5. This condition was believed due to desorption and subsequent evaporation of PEG [17]. In fact, phase transformation from magnetite $\left(\mathrm{Fe}_{3} \mathrm{O}_{4}\right)$ to maghemite $\left(\gamma-\mathrm{Fe}_{2} \mathrm{O}_{3}\right)$ has occurred during this stage. However, the weight gain produced by this phase transformation could not be detected as it is concealed by the remarkable weight loss due to combustion of PEG. The third weight loss in between $450^{\circ} \mathrm{C}$ to $800^{\circ} \mathrm{C}$ was attributed to the phase transition of MNPs. In this stage, the maghemite phase of MNPs was produced during the combustion of PEG and then transformed into hematite $(\alpha-$ $\mathrm{Fe}_{2} \mathrm{O}_{3}$ ) phase [17]. Lastly, the content of coating agent of PEG $(0.6 \mathrm{~g}, 0.8 \mathrm{~g}, 1.0 \mathrm{~g}, 2.0 \mathrm{~g}$, and $3.0 \mathrm{~g})$ coated on MNPs samples was estimated to be about $2.02 \%, 2.83 \%, 3.17 \%, 4.68 \%$, and $5.68 \%$, respectively.

A vibrating sampler magnetometer (VSM) was used to measure magnetic properties of uncoated MNPs sample and PEG coated MNPs samples. The hysteresis curves of the 


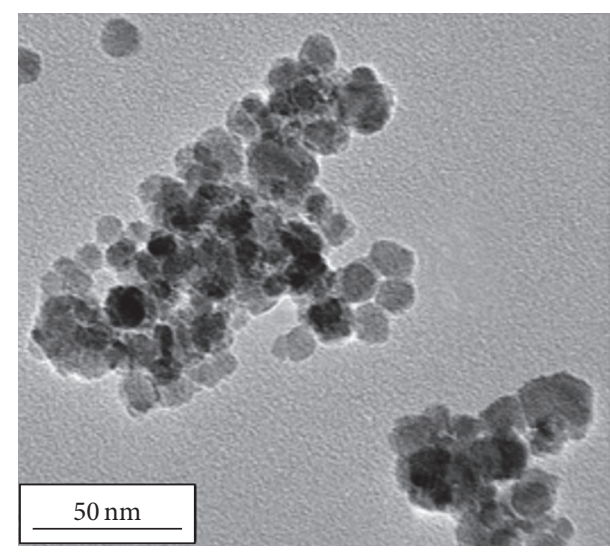

(a)

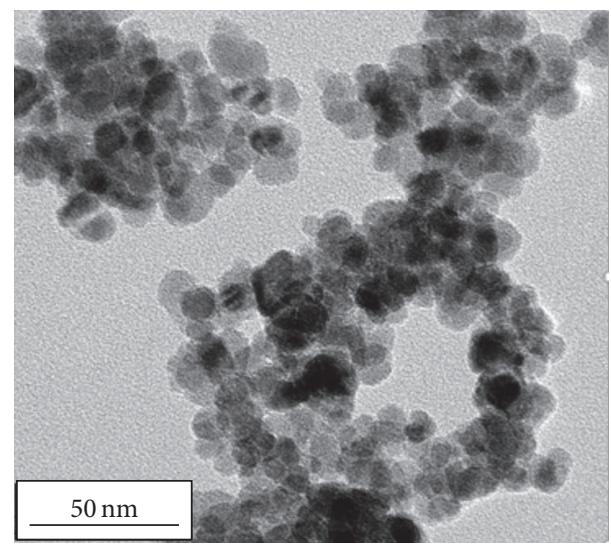

(b)

FIGURE 4: HRTEM images of (a) uncoated MNPs and (b) PEG (1.0 g) coated MNPs samples.

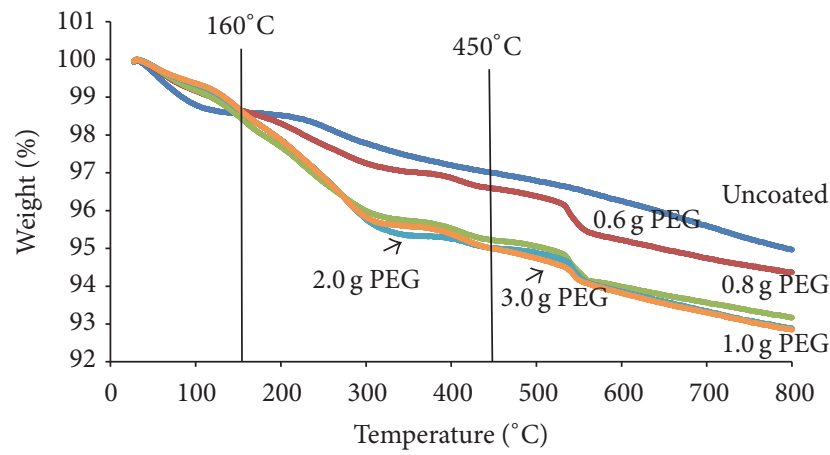

FIgURE 5: TGA curves of MNPs with different loading amount of PEG 600 Da.

synthesized samples were measured at $300 \mathrm{~K}$ and presented in Table 2.

It should be noted that the uncoated MNPs have saturation magnetization (Ms) of $80.23 \mathrm{emu} / \mathrm{g}$ at $10 \mathrm{kOe}$ and a coercivity of $14.71 \mathrm{Oe}$, which are close to the bulk value of magnetite about $85-100 \mathrm{emu} / \mathrm{g}$ and $115-150$ Oe, respectively [22]. The Ms of PEG coated samples was gradually decreased from $66.56 \mathrm{emu} / \mathrm{g}$ to $63.24 \mathrm{emu} / \mathrm{g}$ as the PEG loading amount was increased from $0.6 \mathrm{~g}$ to $3.0 \mathrm{~g}$. These values of saturation magnetization were much larger than the result reported by Anbarasu et al. [15] (51-62 emu/g). The reduction of saturation magnetization of MNPs might be attributed to the reduction of crystallite size of synthesized MNPs and the existence of diamagnetic shell that encapsulated the MNPs $[23,24]$. Overall, all samples showed superparamagnetic behaviour, with coercivity and remanence values less than 10 Oe and $2 \mathrm{emu} / \mathrm{g}$, respectively (Figure 6).

Sedimentation test was carried out to study the colloidal stability of uncoated MNPs and PEG coated MNPs samples in different mediums up to 21 days, including basic medium of $\mathrm{pH} 10$ (water) and nitrile (NBR) latex studies as illustrated in Tables 3 and 4, respectively. Based on the results obtained, it was found that uncoated MNPs started to sediment within

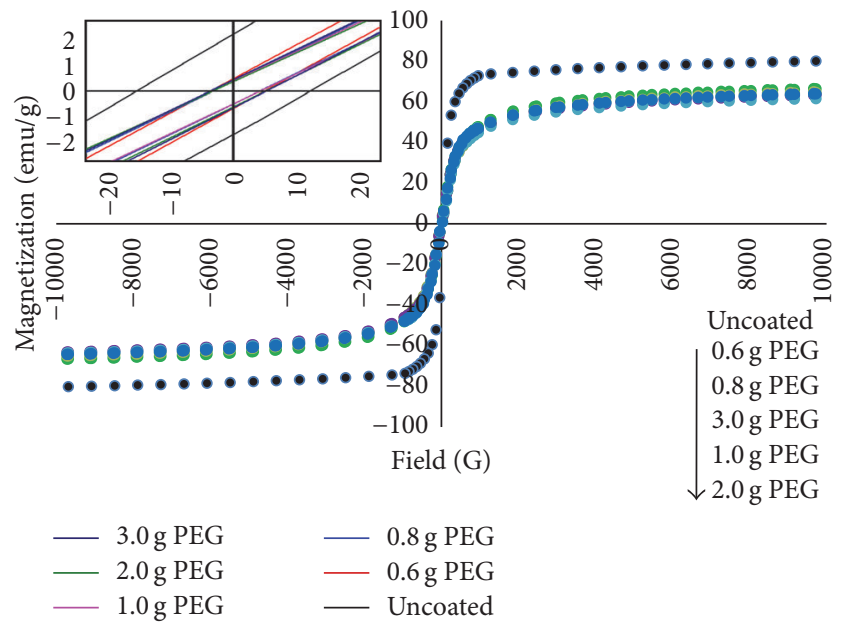

FIGURE 6: VSM hysteresis loop of MNPs with different loading amount of PEG 600 Da.

3 days and complete precipitation in 7 days. In fact, the uncoated MNPs tend to precipitate rapidly due to strong magnetic dipole-dipole attraction between magnetite particles [24]. Interestingly, it was found that addition of $1.0 \mathrm{~g}$ of PEG 600 coated on MNPs exhibited the good colloidal stability in water $(\mathrm{pH}=10)$ and nitrile $(\mathrm{NBR})$ latex solution among the samples. These results clearly demonstrate the significant effects of different PEG contents coated on MNPs samples on the colloidal stability performances. This finding might be attributed to a primary coating layer that is chemically absorbed on the surface of MNPs and eventually formed a stable colloidal solution with high electrophoretic mobility.

\section{Conclusions}

In summary, PEG coated MNPs samples were successfully prepared via a facile in situ coprecipitation technique. It was found that $1.0 \mathrm{~g}$ of PEG coated MNPs exhibited high colloidal stability in a basic solution $(\mathrm{pH}=10)$ and nitrile $(\mathrm{NBR})$ latex 
TABLE 2: Magnetic properties of MNPs with different loading amount of PEG 600 Da.

\begin{tabular}{lcccc}
\hline Sample & Crystallite size $(\mathrm{nm})$ & Saturation magnetization, $\mathrm{M}_{s}(\mathrm{emu} / \mathrm{g})$ & ${\text { Coercivity, } \mathrm{H}_{c}(\mathrm{Oe})}{\text { Remanance, } \mathrm{M}_{r}(\mathrm{emu} / \mathrm{g})}$ \\
\hline Uncoated & 13.6 & 80.23 & 14.71 & 1.79 \\
$0.6 \mathrm{~g}$ & 12.3 & 66.56 & 4.55 & 0.52 \\
$0.8 \mathrm{~g}$ & 11.9 & 65.01 & 3.95 & 0.40 \\
$1.0 \mathrm{~g}$ & 10.7 & 64.12 & 4.75 & 0.50 \\
$2.0 \mathrm{~g}$ & 10.4 & 63.76 & 4.45 & 0.45 \\
$3.0 \mathrm{~g}$ & 9.3 & 63.24 & 4.05 & 0.40 \\
\hline
\end{tabular}

TABLE 3: Sedimentation of uncoated MNPs and PEG 600 coated MNPs in water ( $\mathrm{pH} 10)$.

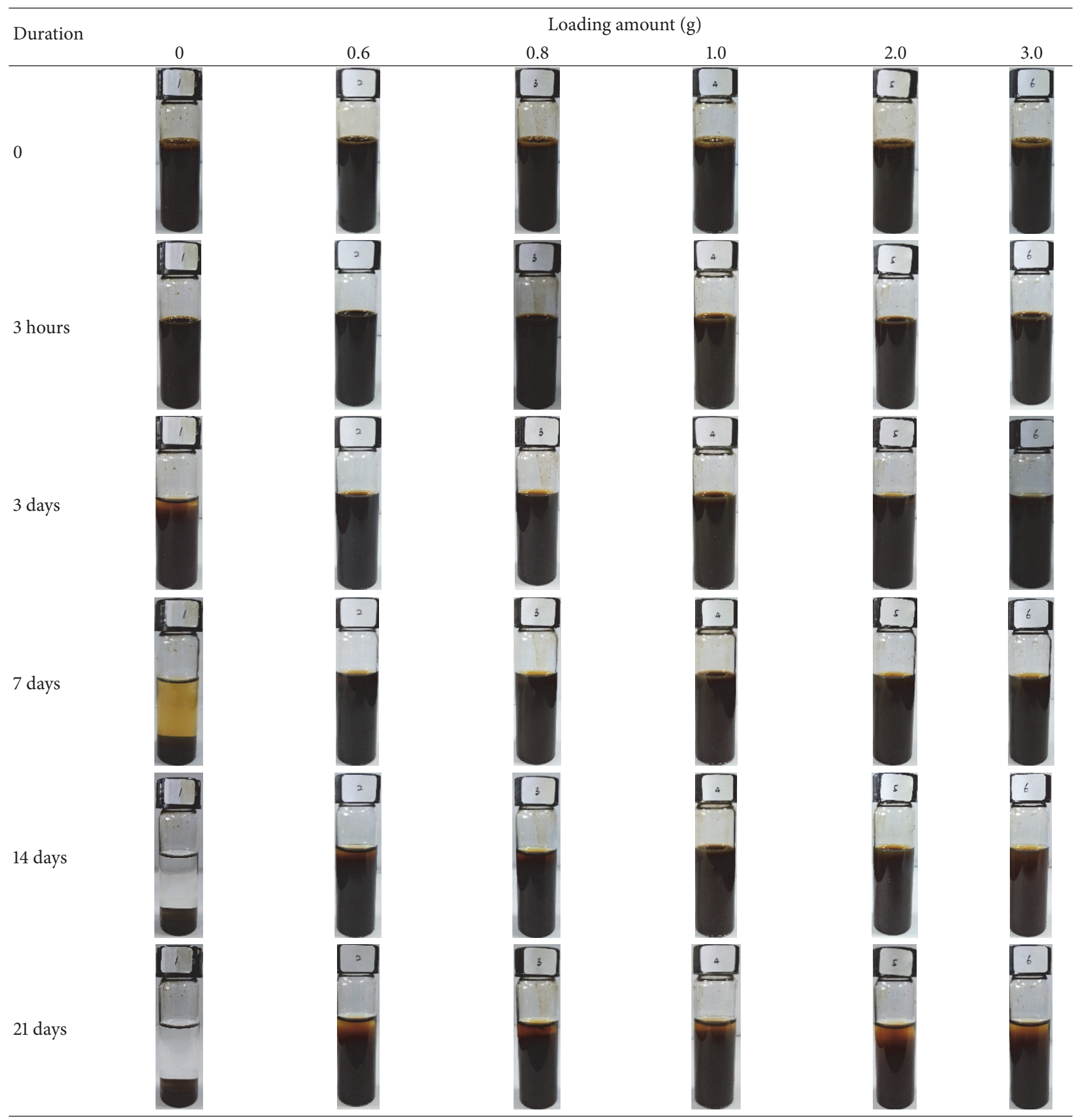


TABLE 4: Sedimentation of uncoated MNPs and PEG 600 coated MNPs in nitrile (NBR) latex.

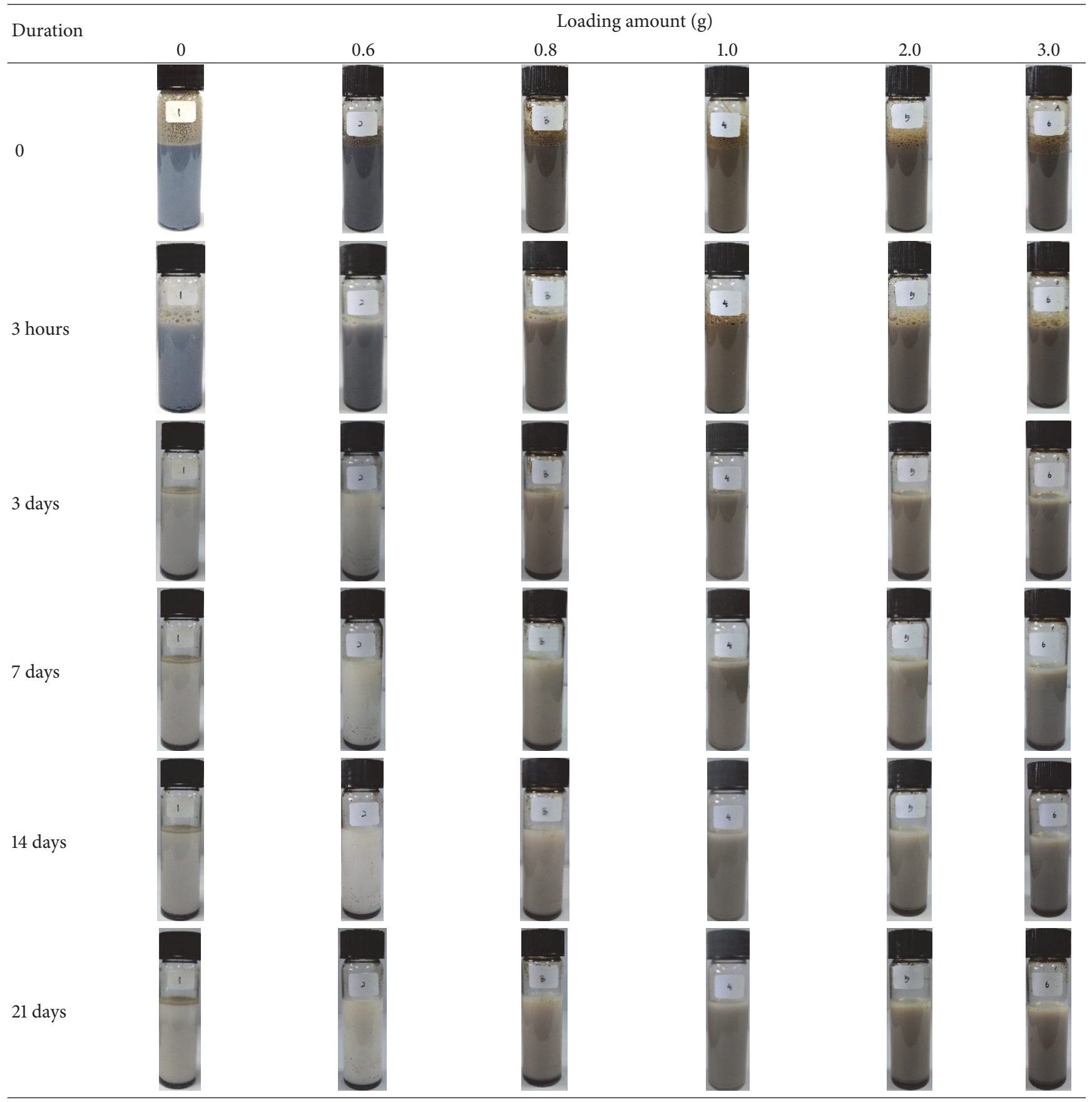

up to 21 days compared to the unmodified MNPs during the sedimentation test. The high colloidal stability with high electrophoretic mobility was found for the $1.0 \mathrm{~g}$ of PEG coated MNPs sample. This resultant sample exhibited a saturation magnetization of approximately $64 \mathrm{emu} / \mathrm{g}$ at $300 \mathrm{~K}$.

\section{Competing Interests}

The authors declare no competing interests.

\section{Acknowledgments}

The authors would like to thank University of Malaya for funding this research work under Prototype Research Grant Scheme (PRGS: PR005-2014A), Fundamental Research Grant Scheme (FRGS: FP008-2015A), and University of Malaya Postgraduate Research Grant (PPP: PG068-2014B). In addition to that, this research was supported by Hartalega Sdn. Bhd. under project Modification of Existing Nitrile Latex with Magnetite Nanoparticles. 


\section{References}

[1] M. Faraji, Y. Yamini, and M. Rezaee, "Magnetic nanoparticles: synthesis, stabilization, functionalization, characterization, and applications," Journal of the Iranian Chemical Society, vol. 7, no. 1, pp. 1-37, 2010.

[2] M. Yu, S. Huang, K. J. Yu, and A. M. Clyne, "Dextran and polymer polyethylene glycol (PEG) coating reduce both 5 and $30 \mathrm{~nm}$ iron oxide nanoparticle cytotoxicity in 2D and 3D cell culture," International Journal of Molecular Sciences, vol. 13, no. 5, pp. 5554-5570, 2012.

[3] M. Nidhin, K. J. Sreeram, R. Indumathy, and B. U. Nair, "Synthesis of iron oxide nanoparticles of narrow size distribution on polysaccharide templates," Bulletin of Materials Science, vol. 31, no. 1, pp. 93-96, 2008.

[4] J.-F. Liu, Z.-S. Zhao, and G.-B. Jiang, "Coating $\mathrm{Fe}_{3} \mathrm{O}_{4}$ magnetic nanoparticles with humic acid for high efficient removal of heavy metals in water," Environmental Science \& Technology, vol. 42, no. 18, pp. 6949-6954, 2008.

[5] J. Koetz and S. Kosmella, Polyelectrolytes and Nanoparticles, Springer, Berlin, Germany, 2007.

[6] S. Meerod, G. Tumcharern, U. Wichai, and M. Rutnakornpituk, "Magnetite nanoparticles stabilized with polymeric bilayer of poly(ethylene glycol) methyl ether-poly( $\varepsilon$-caprolactone) copolymers," Polymer, vol. 49, no. 18, pp. 3950-3956, 2008.

[7] W. Wu, Q. He, and C. Jiang, "Magnetic iron oxide nanoparticles: synthesis and surface functionalization strategies," ChemInform, vol. 40, no. 24, 2009.

[8] E. Umut, "Surface modification of nanoparticles used in biomedical applications," in Modern Surface Engineering Treatments, InTech, 2013.

[9] D. Astruc, Nanoparticles and Catalysis, John Wiley \& Sons, Berlin, Germany, 2008.

[10] D. Ramimoghadam, S. Bagheri, and S. B. A. Hamid, "In-situ precipitation of ultra-stable nano-magnetite slurry," Journal of Magnetism and Magnetic Materials, vol. 379, pp. 74-79, 2015.

[11] L. Huang and K. Nishinari, "Interaction between poly (ethylene glycol) and water as studied by differential scanning calorimetry," Journal of Polymer Science, Part B: Polymer Physics, vol. 39, no. 5, pp. 496-506, 2001.

[12] D. Singh, J. M. McMillan, X.-M. Liu et al., "Formulation design facilitates magnetic nanoparticle delivery to diseased cells and tissues," Nanomedicine, vol. 9, no. 3, pp. 469-485, 2014.

[13] C. Yue-Jian, T. Juan, X. Fei et al., "Synthesis, self-assembly, and characterization of PEG-coated iron oxide nanoparticles as potential MRI contrast agent," Drug Development and Industrial Pharmacy, vol. 36, no. 10, pp. 1235-1244, 2010.

[14] W. Jiang, K.-L. Lai, H. Hu et al., "The effect of $\left[\mathrm{Fe}^{3+}\right] /\left[\mathrm{Fe}^{2+}\right]$ molar ratio and iron salts concentration on the properties of superparamagnetic iron oxide nanoparticles in the water/ ethanol/toluene system," Journal of Nanoparticle Research, vol. 13, no. 10, pp. 5135-5145, 2011.

[15] M. Anbarasu, M. Anandan, E. Chinnasamy, V. Gopinath, and K. Balamurugan, "Synthesis and characterization of polyethylene glycol (PEG) coated $\mathrm{Fe}_{3} \mathrm{O}_{4}$ nanoparticles by chemical coprecipitation method for biomedical applications," Spectrochimica Acta-Part A: Molecular and Biomolecular Spectroscopy, vol. 135, pp. 536-539, 2015.

[16] S. Amala Jayanthi, D. Sukanya, A. Joseph Arul Pragasam, and P. Sagayaraj, "The influence of PEG 20,000 concentration on the size control and magnetic properties of functionalized biocompatible magnetic nanoparticles," 2013.
[17] S. García-Jimeno and J. Estelrich, "Ferrofluid based on polyethylene glycol-coated iron oxide nanoparticles: characterization and properties," Colloids and Surfaces A: Physicochemical and Engineering Aspects, vol. 420, pp. 74-81, 2013.

[18] I. Nyirö-Kósa, D. C. Nagy, and M. Pósfai, "Size and shape control of precipitated magnetite nanoparticles," European Journal of Mineralogy, vol. 21, no. 2, pp. 293-302, 2009.

[19] T.-J. Yoon, H. Shao, R. Weissleder, and H. Lee, "Oxidation kinetics and magnetic properties of elemental iron nanoparticles," Particle and Particle Systems Characterization, vol. 30, no. 8, pp. 667-671, 2013.

[20] C. Y. Wang, J. M. Hong, G. Chen, Y. Zhang, and N. Gu, "Facile method to synthesize oleic acid-capped magnetite nanoparticles," Chinese Chemical Letters, vol. 21, no. 2, pp. 179-182, 2010.

[21] J. Liang, H. Li, J. Yan, and W. Hou, "Demulsification of oleicacid-coated magnetite nanoparticles for cyclohexane-in-water nanoemulsions," Energy and Fuels, vol. 28, no. 9, pp. 6172-6178, 2014.

[22] M. Ma, Y. Zhang, Z. Guo, and N. Gu, "Facile synthesis of ultrathin magnetic iron oxide nanoplates by Schikorr reaction," Nanoscale Research Letters, vol. 8, no. 1, pp. 1-7, 2013.

[23] J. Qu, G. Liu, Y. Wang, and R. Hong, "Preparation of $\mathrm{Fe}_{3} \mathrm{O}_{4}$ chitosan nanoparticles used for hyperthermia," Advanced Powder Technology, vol. 21, no. 4, pp. 461-467, 2010.

[24] M. Mahdavi, M. B. Ahmad, M. J. Haron et al., "Synthesis, surface modification and characterisation of biocompatible magnetic iron oxide nanoparticles for biomedical applications," Molecules, vol. 18, no. 7, pp. 7533-7548, 2013. 

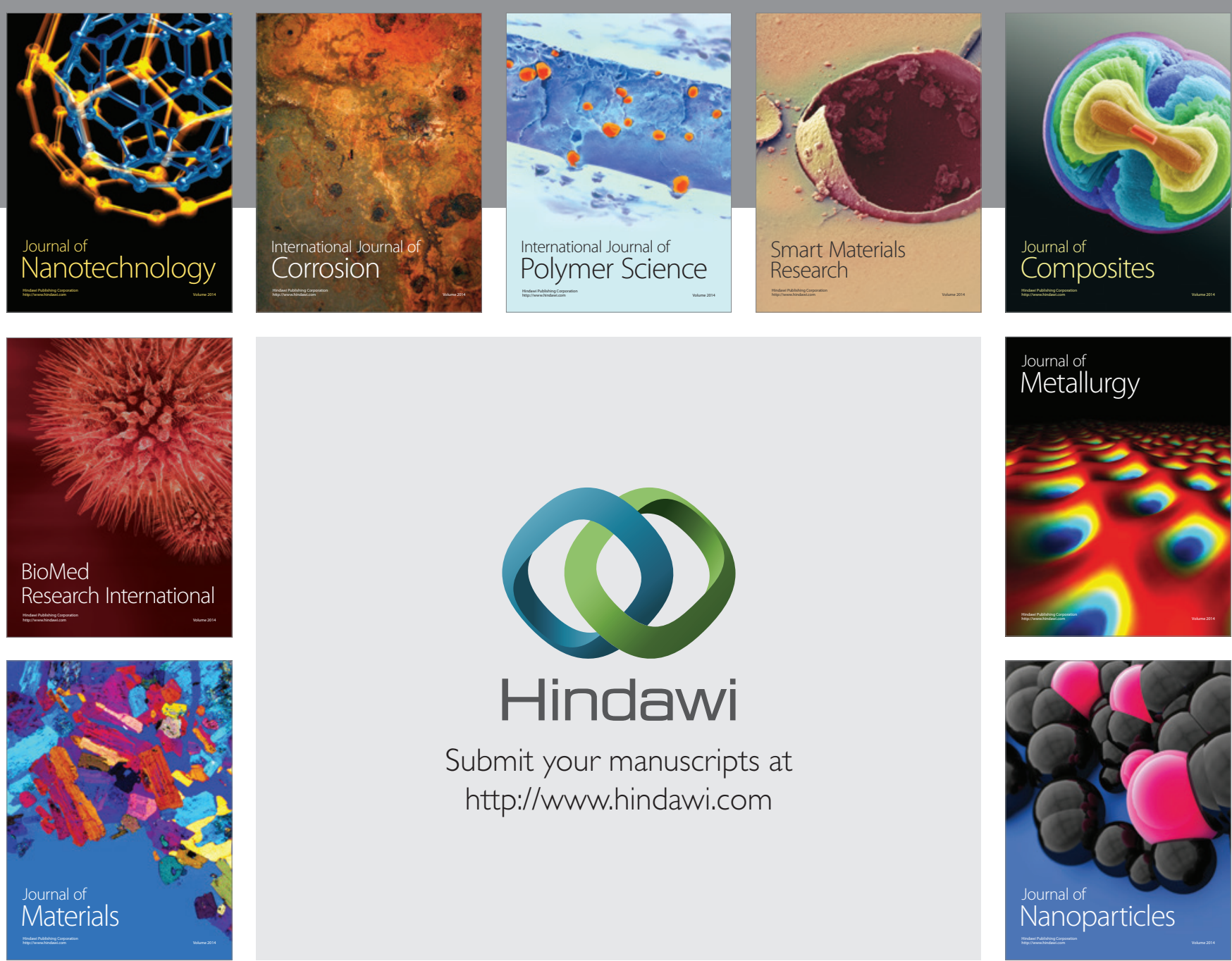

\section{Hindawi}

Submit your manuscripts at

http://www.hindawi.com

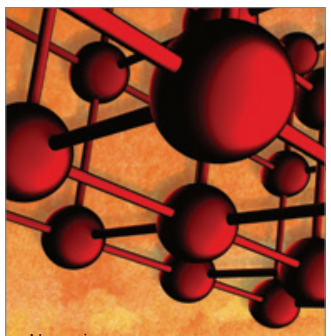

Materials Science and Engineering
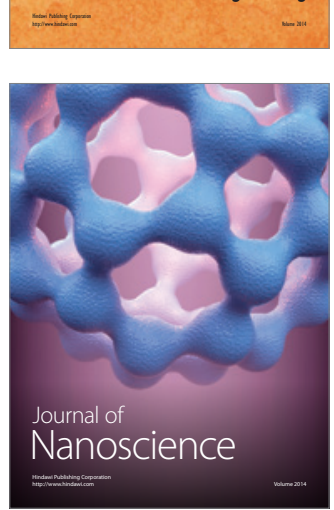
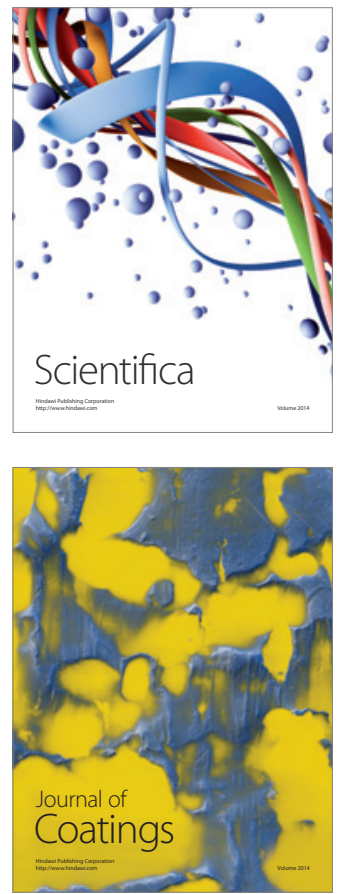
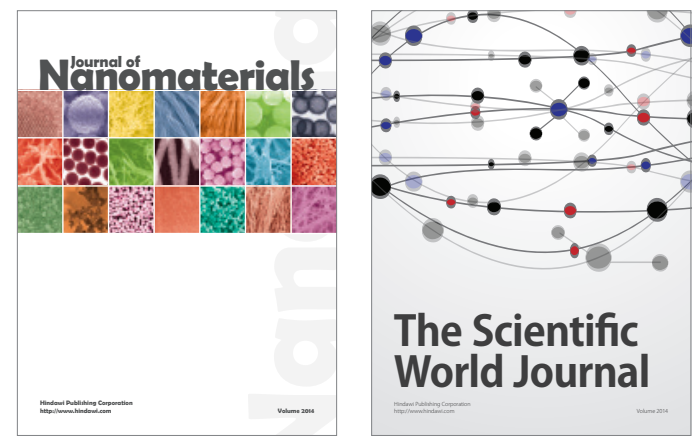

The Scientific World Journal
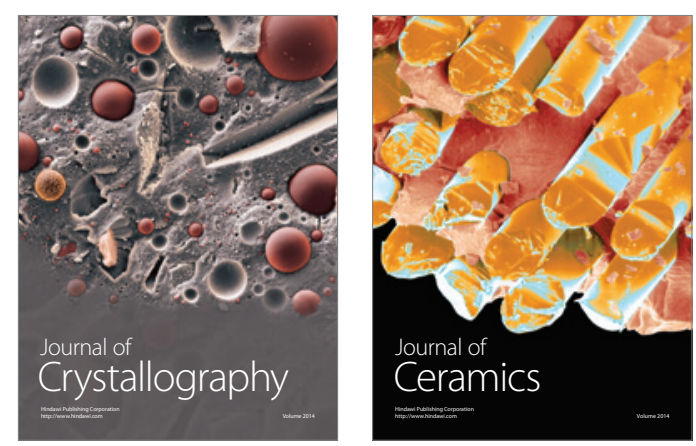
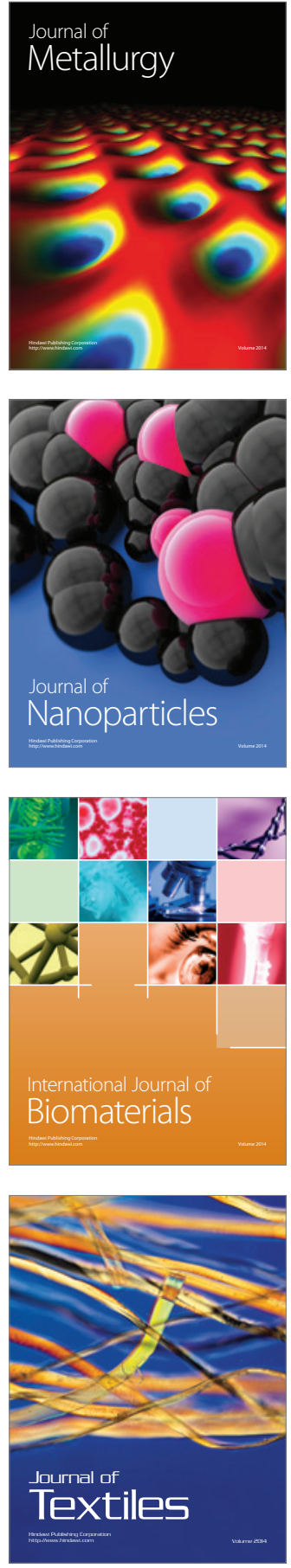